\title{
Actividades agromarítimas en el Noroeste peninsular
}

Veiga de Oliveira, Ernesto; Galhano, Fernando; Pereira, Benjamim: Actividades AgroMaritimas em Portugal (Lisboa: Publicações Dom Quixote, 1990), 236 pp. con 51 dibujos (en realidad 53 y 1 mapa) +174 fotografías en láminas.

Una editorial de nombre y aliento quijotesco ha puesto por fin al alcance del estudioso una colección, significativamente titulada "Portugal de perto», que reúne obras clásicas y modernas de la Etnografía portuguesa, con presentación digna y precio razonable. La que ahora nos ocupa, reimpresión del libro publicado en 1975 por el Centro de Estudos de Etnologia, consta de dos partes: «La recogida de algas marinas» (pp. 1120), que pone al día un viejo artículo de Veiga de Oliveira y Galhano (Trabalhos de Antropologia e Etnologia XVI, 1958); y «La pesca del cangrejo en bancos» (pp. 121180), que es nueva. Siguen unos apéndices, resumen en francés, bibliografía y varios índices: de dibujos, de fotografías - fechadas - y analítico, más una fe de erratas que salva las pocas deslizadas. Detalles materiales nada sorprendentes para quien conozca la rigurosa trayectoria de este equipo de etnógrafos cuyos múltiples trabajos son, como éste, modélicos, y podrían servir para reconstruir, con mínimo margen de error, actividades complejas ya desaparecidas. A eso hay que añadir la prosa sobria y concisa con que el libro está compuesto: un lenguaje poético a fuerza de ser preciso, sin evocaciones nostálgicas y sin asepsias pseudocientíficas, digno complemento del soberano dominio mostrado en la materia, el método y la representación gráfica. Ante obras similares el lector siente que, mediante una labor etnográfica concienzuda, los elementos de la cultura tradicional pueden pasar a ser, como las lenguas clásicas, no algo muerto, sino algo escrito. Lo que de veras muere es el saber depositado en el recuerdo de quienes lo poseen sin que nadie le preste atención ${ }^{1}$.

1 Los artículos o extractos concernientes a la recogida de algas y a las barracas del litoral han sido objeto de breves reseñas en esta revista, obra de J. R. Fernández Oxea (XIV, 1958, p. 521) y J. Pérez Vidal (XXIV, 1968, 192-3). El hecho de haberse ampliado e integrado en libro creemos que justifica una nueva recensión más detallada, sobre todo si se tiene en cuenta que nada similar se ha hecho en nuestro país sobre estas tareas agro-marítimas. Aparte un artículo de periódico referente a la zona de Oya (Pontevedra), los autores citan un único trabajo de carácter general sobre el tema: M. GAvazzI, «Die Nutznießung des Tangs in den Volksüberlieferungen der europäischen Meeresküsten» (In memoriam António Jorge Dias, I, Lisboa, 1974, 123-138). Además, deben tenerse en cuenta los artículos de José Luis PÉREZ DE CASTRO, «Generalidades sobre los fertilizantes en la agricultura tradicional asturiana», Boletín del Instituto de Estudios Asturianos, X, XXXIII (1958), pp. 106-123; X, XXXIV (1958), pp. 264-287; y «Generalidades sobre los fertilizantes 
La recogida de algas para utilizarlas como abono, aunque esporádicamente se da en otros puntos, se practicó sobre todo en la costa arenosa, abundante en arrecifes y bajíos, cortada por las desembocaduras de los ríos Miño, Lima, Cávado, Ave y Duero, es decir, en el litoral de la Galicia portuguesa, donde se documenta ya a comienzos del siglo XIV y ha tenido cierta incidencia en el surgimiento de poblaciones marítimas. Desde un punto de vista antropológico esta actividad presenta un enorme interés, por cuanto 1) se realiza, con aperos específicos y distintos, por labradores para uso propio, o por pescadores para vender; 2) según la zona, con tareas y atuendos bien delimitados para cada sexo; 3) el período de recolección, también variable, se centra en el verano y puede abarcar el otoño, con restricciones eclesiásticas en los festivos, que en el pasado dieron lugar a reglamentación y vigilancia, fuentes a su vez de numerosos conflictos.

Los autores comienzan con este último aspecto en un sabroso capítulo ( «La recogida del sargazo en el pasado. La iglesia y el sargazo») que aprovecha cuantas noticias se han podido espigar sobre el asunto en provisiones reales, documentos municipales y actas de visita a las feligresías durante los siglos XVII y XVIII. Puesto que la iglesia se atribuyó la propiedad de las algas que el mar arrojara -o los particulares cortasenen domingos y fiestas, los párrocos hubieron de designar un guarda jurado -el olbeiroque protegiera sus intereses y regulara el comienzo de la jornada sargacera apagando su farol al amanecer del lunes o primer día laboral. Las penitencias pecuniarias impuestas a los infractores variaban según hubiesen o no oído misa, y en la documentación son frecuentes las acusaciones de negligencia y cohecho, los recursos a autoridades superiores $\mathrm{y}$, por parte de éstas, las amenazas de excomunión ipso facto incorrenda, incluso una eufemística recomendación a los párrocos para que «evitasen» a los morosos hasta que hubieren pagado su multa echando públicamente el importe de ella en la caja destinada al efecto. Se llegó a crear el cargo de contra-olheiro, o vigilante secreto de los vigilantes comunes: tal fue el volumen de medios puestos en movimiento en torno a la economía del sargazo, que, por otra parte, ocasionó continuos disturbios y querellas entre los observantes y los transgresores de las reglas.

La tecnología comprende dos tipos de aperos, para la recogida desde tierra o desde embarcaciones. En tierra se maneja la graveta o gaiteira, que viene a ser una especie de rastrillo con dientes paralelos de madera y púas metálicas perpendiculares al peine. Otros del mismo tipo, usados desde balsas o lanchas, tienen mango de castaño mucho más largo (rastilha), que puede empalmarse varias veces hasta alcanzar los $10 \mathrm{~m}$. (ganchorra), y sus dientes son total o parcialmente de hierro a fin de darle peso para sumergirse y aferrar algas del fondo. En el sector más norteño se utiliza de igual manera el croque, con dientes de hierro divergentes y mango también ampliable.

Otros utensilios recuerdan las artes de pesca: el rodafole o ganbapão, saco de red cónica sujeta en un aro circular o semicircular de madera y provisto de mango, sirve para coger las algas flotantes. Sus dimensiones oscilan: son menores al norte del Lima,

de la agricultura tradicional astur», BIDEA, XIII, XXXIV (1959), pp. 99-113; XIII, XXXVII (1959), pp. 245-260. En la misma colección se han reimpreso obras tan importantes como Aparelbos de elevar a água de rega, de J. Dias y F. Galhano (cf. la reseña de Caro Baroja, RDTP XI, 1955, 187-8), Construções primitivas em Portugal, de Veiga de Oliveira, Galhano y Pereira (cf. Pérez Vidal, ibid., XXVII, 1971, 171-4), y Festividades cíclicas em Portugal, del recién fallecido Oliveira. Aprovechamos para destacar otro libro reciente de Veiga de Oliveira y Pereira, con dibujos de Galhano, titulado Tecnologia tradicional agrícola dos Açores, impreso en 1987 por el Centro de Etudos de Etnologia de Lisboa. 
donde lo manejan sobre todo las mujeres. El arrasto es una estructura cuadrangular de hierro abajo y palo arriba que sirve de boca a un saco de red similar al empleado en la pesca del camarón, aunque de malla más rala. Se arrastra con un cabo desde barcas o desde tierra y luego se vacía con una pala asimismo de red llamada rabichel. El gal. richo, gran saco de red cónica montado en un aro de hierro, lleva como asas un eje diametral y otro radial, y se usa entrando en el agua hasta donde se hace pie. Para cortar las algas aún prendidas en las rocas se utilizaban hoces con hoja en parte de sierra y mango largo. Las algas se amontonaban sobre la línea de marea para luego transportarlas en una especie de parihuelas (carrela o padiola) o en carretillas con ruedas de tablas (carrelos) hasta las dunas, donde se ponían a secar durante unos días, antes de ser almacenadas en palbeiros. Todo el proceso se ejemplifica en vivísimas descripciones correspondientes a diversas zonas: Montedor, Castelo de Neiva, Averomar, etc., con excelente documentación gráfica de cada una de sus fases y elementos.

Viene después un estudio pormenorizado de las embarcaciones empleadas para recoger las algas que no se alcanzan desde la playa. Las gamelas o masseiras, propias del extremo NW, desde Caminha hasta Castelo de Neiva, son barcas sólidas de proa y popa cortadas y fondo plano algo arqueado, con cuatro bancos. Tripuladas por dos hombres, navegan a remo o vela. Al sur de Apúlia se da la catraia, o trainera típica de Póvoa de Varzim, que ha sustituido un barco de proa y popa aguzadas y fondo chato antes usado en la costa de Esposende.

Muy numerosas en otro tiempo fueron las balsas (jangadas), de las que aún quedaban ejemplares hacia 1970 en Castelo de Neiva. La balsa consiste en una armazón de bastos troncos de chopo ligados por dos traviesas, y posee unos rebordes laterales que impiden resbalar a las algas recogidas. En los troncos extremos se han practicado unos huecos para que pueda agarrarse mejor al transportarla; también se dispone sobre un eje con ruedas (rodado), que al botarla se deja a la orilla. En el agua se gobierna con una vara y lleva una o dos personas. En Marinhas y Sedovem hay balsas hechas con paneles de corcho sujetos con alambre, entre tablas unidas por listones. Otras, aún más primitivas (cortiços), constan de cuatro rollos de corcho igualmente sujetos con alambre y atravesados por dos palos. Se usaron en Averomar sólo en la recogida de algas.

Barcos, balsas y demás aperos se guardaban en barracas, cuya tipología se establece con detalle a partir de lo subsistente. Las de labradores primero fueron de piedra con cobertura de paja (colmo), luego sustituida por tejas, a dos o cuatro aguas: así en Angeiras, Mindelo y Vila Chã. Las de Aguçadoura en cambio eran enteramente de madera y más amplias, mientras que en Fão adoptan una curiosa planta elíptica, con tejado a tres aguas. Al norte de Viana do Castelo las formas son más irregulares y variadas, de piedra o madera y tejados de una a cuatro aguas.

Los sargaçeiros usaron marcas propias para sus utensilios, y un traje específico, la branqueta, que es en el hombre una casaca de lana cruda, larga hasta las rodillas, abotonada por delante y ceñida con cinturón, sin ropa debajo, como corresponde a una actividad que requiere larga permanencia en el agua. El de la mujer consta de dos piezas, blusa y falda corta.

En el apéndice I se da la lista de palabras usadas para designar las diferentes especies de algas de la zona (botelbo se aplica a ocho distintas), así como la descripción científica de cada una. Entre las feofíceas (algas pardas) más apreciadas y comunes a la costa atlántica española están las cintas o correa de mar (Himanthalia lorea Lymgb.), el botelbo, o fucus vesiculosus (Lin.), así llamado por sus pequeños flotadores aeríferos, y el taborrão, o laminaria azucarada (Lam. saccharina Lamour), que es la que alcanza mayor 
tamaño; semejante a ella, pero con ramificaciones convergentes, es la correa, denominada rabo negro (Lam. Cloustoni Edmondst). Entre las rodofíceas (algas rojas) hay múltiples variedades, de las que son corrientes el argancinho das lapas (Laurencia pinnatifida Lamour), llamada en español pimienta dulce, y el botelho macio o argaço risso (Halarachnion ligulatum Kutz). Unas páginas antes se estudia el porcentaje en nitrógeno, ácido fosfórico, calcio y potasio existente en algas y cangrejos, y su aplicación como abono en patatales y viñedos, o en áreas de dunas antes improductivas, lo que lleva a consideraciones ecológicas del mayor interés, en relación con la llamada agricultura orgánica o biológica, cuyas orientaciones «preconizan la utilización de fertilizantes naturales, que enriquecen los suelos y, de ese modo, aumentan la resistencia y la vitalidad de las plantas, por oposición a los abonos químicos, los cuales, a largo plazo, producen efectos nefastos» (p. 186). Claro es que el aprovechamiento de las algas exige respetar unas condiciones que no empobrezcan la naturaleza - todo lo contrario de lo que se hace hoy día en algunos lugares, con equipos de submarinistas que arrasan lo que encuentran para usos industriales.

La segunda parte del libro se consagra a la pesca del pilado, o patelo, nombres con que se designa en Portugal el Portunus puber L., (Polybius Henslowi Leach), pequeño cangrejo rojo, no comestible, que tiene anchas y planas el último par de patas, con las que nada, y se desplaza en bancos por la plataforma litoral. A diferencia de lo que ocurre con la recogida de algas, no se poseen referencias a la pesca del pilado anteriores al siglo XIX, y ha dejado de practicarse progresivamente desde 1940 hasta la década de los sesenta, por haber desaparecido de la costa, bien a causa de corrientes marinas, o por efecto de las grandes artes de arrastre, aunque no falta quien asegure que sigue existiendo, pero que fue desplazado por los abonos químicos, una vez comenzada la crisis de la vieja economía familiar y cualitativa. En Portugal se pescaba en los meses de julio a diciembre desde el Miño hasta Nazaré; en la costa del Alentejo y del Algarbe era conocido, pero no como fertilizante sino como factor perjudicial, que ahuyentaba los bancos de sardina. La pesca se hace con red barredera que se prende a un elemento inmóvil, boya o barco fondeados, y se larga desde un barco hasta cerrar el cerco volviendo al punto de partida. Entoces se hala la red y al aflorar el copo se embarca el cangrejo con salabardos. Cuando se emplean dos barcos (al norte del Duero, principalmente), éstos pueden ser iguales o distintos; en este caso el pequeño cala la red mientras el grande permanece inmóvil. En unas zonas la faena la realizaban labradores, auxiliados o no por pescadores; en otras (área de la jábega, de Espinho a Nazaré) eran solamente los pescadores quienes se dedicaban a esta actividad durante la noche o en horas libres. Normalmente, aunque no siempre, el dueño del barco y los aparejos hacía de patrón (arrais). Los barcos mayores (lanchas) tenían de 8 a 12 remos, movido cada uno por dos hombres. Los pequeños ( $N$. del Duero), de 2 a 4 remos; un hombre con dos remos a proa o a popa y los restantes con uno. Cuando el número era impar, es que el patrón se sirve de un remo como timón. Los grupos, entre los que se creaba una solidaridad especial, estaban constituidos por hombres; como excepcional se cita el de Vila Chã, donde pescaban las mujeres y hasta conseguían carta de patrón.

La red es similar a la utilizada para la sardina, con malla más ancha y muchos más plomos a fin de raspar los fondos arenosos donde se entierra el cangrejo. Tiene un saco central o copo en forma algo cónica de 3 a 5 brazas de largo, con una bocana cuadrada de 1,5 a 3 brazas de lado, aunque puede ser redonda, rodeada de guardas y fisgas. A ambos lados del copo, y formadas por varios paños de malla aún más ancha, se extienden las mangas, que miden de 20 a 30 brazas cada una y se van estrechando 
hacia los extremos. En los bordes de las mangas van las relingas (tralhas); la superior lleva las boyas redondas o cuadrangulares de corcho, de unos $10 \mathrm{cms}$., y la inferior, los plomos, que pueden ser también de otros materiales. Las relingas se unen con un palo vertical llamado calón (calão), del que parten dos cuerdas para enlazar con los grandes cabos de la red, de 50 a 120 brazas de longitud; el que cierra el cerco solía ser algo más largo.

Cuando la pesca se realizaba con dos barcos, una vez completado el cerco, las proas quedaban orientadas hacia el ancla, y separadas unas 10 brazas. Entonces dos o tres hombres iban recogiendo los cabos, con ayuda de poleas, mientras el patrón contaba las marcas - puestas cada diez brazas - para que ambos barcos comenzaran a halar la red al mismo tiempo. Al llegar las mangas un hombre recogía los corchos y otro los plomos. Entretanto los barcos se habían ido aproximando, y cuando salía el copo estaban juntos, formando ángulo. Entonces se vaciaba con rabicheis o pequeños salabardos. La parte de red del barco parado se pasaba al otro y se procedía a un nuevo lance. Si el banco era denso, podía bastar con tres lances para llenar un barco grande. Una vez llenos los dos, el pequeño cargaba con la red, se soltaban las anclas y se emprendía el regreso.

Para pescar con un solo barco se echaba el ferro, cuyo cabo, de 25 a 50 brazas, quedaba ligado a una boya, generalmente un odre provisto de una campanilla para ser localizada en caso de niebla. La boya servía de elemento inmóvil del cerco. Una vez terminado, se halaba la red simultáneamente a proa y a popa, por dos o tres hombres en cada lugar. Mientras se vaciaba el copo un hombre iba apartando el pescado que venía con el cangrejo. En ocasiones al aportar en playas desabrigadas, si el mar era vivo, o si había bajíos, se llenaban unos grandes sacos de red con parte del cangrejo pescado (saco de vaivem), y cerrados y amarrados con un cabo fuerte se lanzaban al agua para aliviar la carga del barco, que los traía a remolque.

Varados ya o atracados los barcos, la descarga la hacían las mujeres que habían bajado a la playa con los carros de bueyes provistos de adral (caniço), los cestos y la merienda. Los hombres, a bordo, llenaban los cestos, y ellas los transportaban en la cabeza hasta los carros. Cada barco de tipo norteño podía cargar de 2 a 3 carros de una tonelada. Los de más al sur unos 6,8 , y alguna lancha grande, 15. Las mismas yuntas servían para arrastrar las embarcaciones hasta lo alto del arenal.

Los campesinos comarcanos acudían normalmente a comprar el pilado. Cuando era necesario conservarlo se mezclaba con arena, salándolo o secándolo para que no se pudriese con el aire y la lluvia. El secado se hacía extendiéndolo en la playa, o en la era, donde luego podía triturarse con mayal. El producto de la venta, descontados impuestos, pagos a los labriegos que pusieran en seco los barcos y vino para la tripulación, se dividía en quinhöes, o partes, tantas como hombres, más las que correspondiesen, según costumbres locales, al barco y aparejo, y a las funciones patronales.

Los barcos con que se pescaba el pilado se clasifican en dos grupos: A) tipo lancha poveira (la de Póvoa de Varzim), que es un barco grande con quilla, roda, codaste y timón, navega a vela o remo y presenta dos subtipos: a) el barco do pilado, propiamente dicho, aunque también iba a la sardina, de Póvoa de Varzim hacia el norte; mide 8,10 de eslora por 2,90 de manga, carece de partes cubiertas a proa o popa, posee cinco bancos -el de proa muy ancho-y horquillas para sujetar la verga de la vela latina. Para llevarlo al agua o subirlo a la barraca se usaban unas pranchas ensebadas con forma de escalera, de unos 5 metros, con travesaños curvos por donde se deslizaba la quilla. Este barco iba acompañado de una pequeña chalana de popa cortada y fondo 
chato. b) El miranço, usado de Póvoa de Varzim hacia el sur, semejante al anterior, aunque mucho más ligero, y de popa más aguzada; no se pintaba sino que se protegía con una capa de resina y sebo dada en caliente. B) tipo barco do mar del litoral central, que tiene fondo chato, roda y codaste en pico elevado (forma de media luna), como los que andan a la jábega en la costa de Aveiro; navega a vela o remo. Presenta cinco subtipos: a) bateira de Afurada, en el estuario del Duero, su límite septentrional. Es apropiado para usar en playas con mucha rompiente. Se trata de un barco alargado con proa erguida en punta, y espacio cubierto a proa que sirve para guardar la vela (antes cuadrangular, luego latina), la ropa y la comida. Las cuadernas de proa y popa se cubren con unos paneles de tabla (paneiros), mientras que en el centro quedan al descubierto para achicar. Lleva dos remos y un pequeño timón. Sus dimensiones normales son 8 m. de eslora, 1,90 de manga y 0,60 de puntal en el centro. b) bateiras de la ría de Aveiro: mercantel, labrega y caçadeira. c) bateira do mar, usada en Costa de Lavos: es un barco de media luna, con fondo chato muy arqueado, proa y popa muy erguidas, de sección romboidal; se impulsa con dos remos. d) bateira de Buarcos. Tiene dos bancos, fondo chato, proa y popa poco elevadas por no ser necesarias en mares abrigados. e) barco de bico, de Nazaré. Muy sólido, con 4,70 de eslora y la mitad de manga, fondo chato y curvado a proa, que termina en pico agudo, mientras que la popa es cortada y ancha. Llevaba dos remos, y modernamente, cuatro.

En la ría de Aveiro se usaron otras formas de pesca, como cerco simple hecho por una bateira, cuya red luego se halaba desde tierra, o la mugiganga, con redes llamadas chinchorros. El cangrejo de ría, aunque comestible, también se empleaba como abono. Con redes más pequeñas, chinchas, los pobres pescaban también pequeños peces destinados a la alimentación y a los viveros.

Para terminar, y en vista de que no hay estudios sobre el tema para la restante costa atlántica de la península, trataremos de aportar algunos datos correspondientes a un punto de Galicia donde las actividades agro-marítimas estaban en auge durante nuestra juventud, y constituían también un espectáculo animado y pintoresco. La pequeña ría de Cedeira (La Coruña), situada al $\mathbb{W}$ del cabo Ortegal $\left(43^{\circ} 39^{\prime} \mathrm{N}, 8^{\circ} 05^{\prime} \mathrm{W}\right)$, y comprendida entre las puntas Chirlateira al W (parroquia de Pantín) y Candieira al NE, es el primer refugio que se abre al norte del Ferrol, en una costa abrupta cortada por largos arenales. En ella desaguan cinco ríos de escaso caudal: de SW a NE, el río das Forcadas, que antes de ser interrumpido por un embalse movía el molino de la Ferrería, entre los términos de Pantín y Vilarrube; su desembocadura recibe el nombre de Ribeiro. El río das Mestas, más considerable, que forma un amplio estuario (gall. esteiro), hábitat o lugar de paso de garzas, patos y avefrías, muy apropiado para la cría del marisco; en él vierten también los riachuelos Gumil y San Miguel, que riegan la parroquia de Esteiro. Entre los ríos das Forcadas y das Mestas queda la playa antes llamada de Loira, hoy de Vilarrube, por la aldea que - según etimología popular el topónimo- trepa Castro arriba hasta el chao do Cruceiro, y a la que vamos a referirnos. Siguiendo hacia el NE, tras el cerro boscoso que forma punta Robaleira (Monte das Croas), se extienden las playas de San Isidro y da Sonreira, en cuyo extremo norte desemboca el río Condomiñas, ya en Cedeira, pequeño puerto pesquero muy abrigado y vila por antonomasia en toda la comarca.

La franja costera de los ayuntamientos de Narón, Valdoviño y entorno de Cedeira vive sobre todo de la agricultura, y algo de los bosques, primero de castaños, luego de pinos y recientemente de eucaliptos. Por lo demás, su economía, frágil y primitiva, acaso ya desde el siglo XVII tuvo su fundamento en el maíz, como se vio en las hambres que 
sobrevinieron por su escasez tras la guerra civil, y como demuestra el que no exista casa vieja sin hórreo en mejor o peor estado de conservación. Tampoco se pueden olvidar, como en cualquier otro punto del ámbito rural gallego, los esquilmos del ganado bovino y ovino, que sometían a los labriegos a una dependencia continua y semejante a una fatalidad: en Vilarrube, por ejemplo, aparte de realizar por igual, hombres y mujeres, las tareas domésticas de cría y ordeño, y de hacer fructificar unas tierras por lo general menguadas y demasiado pendientes, debido a esa orografía se pasaban buena parte del año bajando hasta el amanso - un amplio prado comunal a orillas del estero mayory subiendo de nuevo hasta casa, siempre al mismo paso tardo de las vacas, sueltas o uncidas al carro, por corredoiras llenas de fango. Las viviendas estaban pensadas, en primer lugar, para el ganado, y las condiciones sanitarias eran, en consecuencia, nulas. En resumen, alli la pobreza y el atraso, que nunca empañaron la hermosura de un paisaje soberbio, suponían para los escasos visitantes veraniegos - tres o cuatro familias de raíces autóctonas- oportunidad única de observar, a mediados del siglo $\mathrm{xx}$, formas de vida medievales, si no anteriores.

El mar, cambiante y omnipresente, no pasaba de ser un elemento más. Los campesinos, excluidos a la vez de sus riquezas y peligros, sólo obtenían de él un clima suave, que permite crecer variedad de frutales, incluidos limoneros, y también frecuentes nieblas consideradas nocivas para los cultivos. La playa y los esteros, con grandes áreas descubiertas por la bajamar, les servían ocasionalmente para pescar sollos y anguilas, o coger berberechos, almejas, coquinas y mejillones. Sin embargo es la recogida de algas, y sobre todo la pesca del cangrejo en bancos, allí denominado patexo, lo que tuvo mayor incidencia en la agricultura de la zona, y lo que relaciona este rincón de las rías altas con la actividad desarrollada en Portugal y antes descrita. El breve informe que ofrecemos a continuación se basa en datos suministrados por un campesino de Vilarrube, José Pita Senra, de 69 años, que empezó a ir al patexo en 1937, tiene carta de patrón y ha trabajado también en el transporte de la madera.

Según sus recuerdos, el aprovechamiento de las algas se hizo desde siempre, aunque no se cortaban de las rocas, sino que se recogían las que el mar arrojaba a la playa. La más abundante allí es un alga clorofícea llamada en español lechuga de mar (Ulva lactuca) por su color y bordes rizados: en gallego, xebra verde, que al secarse se pone blanca. Las restantes algas, principalmente laminarias y fucus vesiculosus (llamado barbouzón en Cedeira), reciben el nombre de xebra roiba. La verde era preferible en junio y julio, mientas que la roiba sólo se recogía a partir de agosto y septiembre si no había patexo aquel año. El utensilio empleado era el rastrillo (enciño) con dientes de madera o de hierro. A veces entraban en el agua para pescar la xebra roiba flotante con un cesto da xebra, que es profundo y tiene dos asas arriba o tras dos abajo para ser arrastrado, manteniendo la boca en posición vertical, entre dos personas. En la arena marcaban con el peine del enciño la huella que señalaba la propiedad de la xebra recogida. Luego se cargaba en carros chillones, tirados en la región por yuntas de vacas. Cuanto más mojada viniese la xebra, más se estimaba, por su riqueza en salitre. Una vez cubierta con tierra y podrida, criaba unos gusanos que los estorninos acudian a comer. Se echaba sobre todo en las huertas de coles, patatales y maizales.

En cuanto al patexo, que dejó de pescarse hacia 1965, sus noticias son que se encontraba en pocos lugares, todos próximos a la ría, y a ellos venían a buscarlo labradores o pescadores de lejos: Sada (ría de Betanzos) y Mugardos (ría del Ferrol), principalmente, en lanchas motoras. Los de Pantín, Vilarrube y Cedeira navegaban a vela o remo. A comienzos de siglo, y sin duda antes, iban al mar en grandes barcos de vela llamados 
lanchas, que medían unos $20 \mathrm{~m}$. de eslora, llevaban 7 hombres y cargaban unas 7 toneladas, es decir, 14 carradas. Estas lanchas llegaron hasta la guerra civil. Después se usaron traineras, más pequeñas, con quilla, roda y codaste, proa aguzada y popa redondeada, tripuladas por 4 ó 5 remeros y con capacidad para 3,5 toneladas ( 7 carradas); también chalanas de fondo plano, movidas siempre a remo, con 3 ó 5 hombres a bordo, y que cargaban hasta 3 toneladas ( 6 carradas).

Salían al mar desde mediados de agosto, y los días de calma continuaban yendo hasta bien entrado el invierno, a comienzos de enero. Nunca se alejaban demasiado. En dirección NE podían llegar hasta las puntas Tarroiba y del Cuadro, al pie de los enormes cantiles que hay por San Andrés de Teixido; hacia el SW no solían rebasar la punta Frouxeira, y con frecuencia pescaban a la altura de Marnela, frente a las playas de Pantín. El patexo llevaba siempre rumbo $S W$ y a veces pasaba de largo sin entrar en la ría. Venía entre aguas, nunca a más de 20 brazas, y se metía en los coídos, o ensenadas pedregosas. Con mar vivo se enterraba en la arena. Los labradores conocían su presencia por las gaviotas, que revoloteaban en grandes bandadas siguiendo su curso.

Las embarcaciones de Vilarrube estaban en los esteros, casi siempre en el del río das Mestas, más profundo, llamado Sagres (y pronunciado Sajres) por los lugareños, aunque a veces se encontraban en el Ribeiro por no haber podido entrar en la otra barra, muy batida por la rompiente. Zarpaban aprovechando la pleamar de la tarde y se dirigían a la zona donde habían observado el ajetreo de las gaviotas. La pesca se hacía de noche para que no se viese el aparejo. Usaban un risón unido a una boya por un cabo de 20 a $30 \mathrm{~m}$. Las boyas eran de corcho, e iban provistas de una campanilla. No llevaban luz alguna. Cuando los tripulantes advertían la proximidad de otro barco encendían la mecha de un chisqueiro para hacer señales. Por la proa largaban la veta unida a la boya, que era de unas 40 brazas, luego el calón y una de las pernas de la red (bou), que tenía unas 14 brazas de largo. Después el copo, de malla más tupida, que medía 1,5 brazas de ancho por 1 de largo, y su bocana era un cuadrado de 3 brazas de lado; luego la otra perna, y así hasta completar el cerco. En la veta superior (entrallado) iban los corchos y en la inferior los plomos, estos en cantidad suficiente para que el aparejo rascase el fondo y desenterrase el patexo escondido. Si el mar estaba en calma se aumentaba el número de plomos. Una vez halada la red y aflorado el copo, se descargaba con el salabardo, red cónica montada en un aro que tiene una boca de $0,5 \mathrm{~m}$. y un mango. Podían permanecer hasta 12 horas en el mar, sin más comida que pan de maíz (broa o borona), un trozo de tocino o carne de membrillo, y agua dulce. El regreso, con las traineras cargadas, era duro para los remeros, aunque al ir sumergidas casi hasta la borda sufrían menos los embates del viento. Calculaban o aguardaban el momento próximo a la pleamar, a fin de poder entrar en la barra sin varar en los bolos, o bajíos arenosos, y llegar con las traineras lo más cerca posible de los carros, que los familiares, generalmente mujeres, habían traído hasta el estero provistos de tañeiras o caínzos, es decir, adrales de mimbre.

El quiñón, aquí llamado pila, era de dos carradas; correspondía una pila a cada tripulante, más otra al dueño del barco. El patrón no recibía trato especial. Hecho el reparto y cargados los carros, se sobordaban las traineras o chalanas, es decir, se subían sobre la línea de marea para repintarlas. Los aparejos (remos, anclas, redes y salabardos) se guardaban en casa.

El patexo se echaba en las rozas (monte cavado y quemado para sembrar cereales), en las huertas de coles, sobre todo al poner una nueva, en los rastrojos (restrebas) donde se iban a sembrar plantas forrajeras, y, después de cosechado el maíz, en lo que 
llamaban trigo de chao. El sobrante se vendía: hacia 1950 costaba a 50 y 60 pesetas el carro. Los pescadores de Cedeira lo traían al Alfonil (< árabe, alburi), antiguo depósito situado sobre el estero del Riberio. El patexo esparcido en las fincas requería ciertos cuidados. Primero se cubría con tierra, pero aún así las gaviotas acudian a comerlo, por lo que era necesario urdir el terreno, es decir, clavar palos que se unían con hilos. Otras veces apelaban a un procedimiento más drástico: con un cangrejo prendido a un anzuelo como cebo, "pescaban» una gaviota, la mataban y la dejaban allí para que sirviese de espantajo.

ANTONIO CARREIRA 